\title{
Moderns övervikt och fetma och risker för barnet
}

\author{
Sven Cnattingius \\ Enheten för klinisk epidemiologi, Institutionen för medicin Solna, Karolinska Institutet, Stockholm, Sverige \\ sven.cnattingius@ki.se \\ This is an open access article distributed under the Creative Commons Attribution Licence, which permits unrestricted use, distribution, and reproduction \\ in any medium, provided the original work is properly cited.
}

Övervikt och fetma definieras med hjälp av "body mass index" (BMI), som uträknas genom formeln: vikt $(\mathrm{kg}) /$ längd i meter ${ }^{2}$. BMI indelas i grupper (Tabell 1).

Förekomsten av övervikt och fetma har ökat i de flesta länder under de senaste deccenierna. Idag är mer än $50 \%$ av gravida kvinnor i USA och mer än $30 \%$ av gravida kvinnor i Sverige överviktiga eller feta ${ }^{1,2}$. Förekomsten av allvarlig fetma (grad II-III) ökar fortfarande och är ett växande hälsoproblem ${ }^{3}$. Bland kvinnor i de flesta låginkomstländer är övervikt mer vanligt än undervikt ${ }^{4}$.

För modern innebär övervikt och fetma ökade risker för en rad komplikationer under graviditet och förlossning. Risken för graviditetsdiabetes ökar markant med BMI, men magnituden av riskökning varierar mellan studier, sannolikt till stor del på grund av olika definitioner. Riskerna för graviditets-inducerad (ickeproteinurisk) hypertoni, preeklampsi och tromboemboliska sjukdomar ökar också med moderns BMI. Delvis på grund av dessa graviditetskomplikationer har överviktiga och feta mammor ökade risker för inducerad förlossning, planerat och akut kejsarsnitt ${ }^{5}$.

I Sverige finns sedan 1992 uppgifter om moderns vikt och längd vid inskrivningen till mödravårdscentralen (i regel vid 8-14 graviditetsveckor) i Medicinska Födelseregistret (MFR). Genom barnets personnummer kan MFR länkas till andra register och barnets

Tabell 1. Definition av BMI kategorier.

\begin{tabular}{lrcc}
\hline & & \multicolumn{2}{c}{ Normal längd $(167 \mathrm{~cm})$} \\
\cline { 2 - 4 } \multicolumn{2}{c}{ BMI kategori } & Vikt $(\mathrm{kg})$ & BMI \\
\hline Undervikt & $<18.5$ & 50 & 17.9 \\
Normal & $18.5-<25$ & 65 & 23.2 \\
Övervikt & $25-<30$ & 75 & 26.9 \\
Fetma grad I & $30-<35$ & 90 & 32.3 \\
Fetma grad II & $35-<40$ & 110 & 35.8 \\
Fetma grad III & $>40$ & 115 & 41.2 \\
\hline
\end{tabular}

hälsotillstånd följas. Patientregistret innehåller uppgifter om tidpunkter och diagnoser för all sluten sjukhusvård i Sverige sedan 1987, och diagnoser från öppenvård vid sjukhus finns sedan 2001. Genom Dödsorsaksregistret erhåller vi information om tidpunkt och orsak till död. Genom Flergenerationsregistret kan vi erhålla information om första gradssläktingar (föräldrar, syskon, och barn) och begränsa jämförelsen till barn som är helsyskon eller barn till mammor som är helsyskon. Information om utbildning erhålls från Utbildningsregistret och information om moderns födelseland och emigration från Befolkningsregistret.

Genom dessa datakällor har vi gjort ett flertal befolkningsbaserade studier på samband mellan moderns BMI i tidig graviditet och risker för barnet: prematuritet, spädbarnsdödlighet, asfyxi-relaterade neonatala komplikationer, missbildningar, $\mathrm{CP}$ skador och epilepsi. Vi har också studerat om viktförändringar mellan graviditeter påverkar risker för barnet. Risker har beräknats med hjälp av Odds Ratios (OR) eller Hazard Ratios (HR) som i regel har justerats för moderns ålder, födelseland, utbildningsnivå, samboende med barnafadern (i tidig graviditet), längd, rökning, och år för förlossning.

Jämfört med normalviktiga kvinnor (BMI 18.5-<25) ökar risken för prematur förlossning med övervikt och fetmans allvarlighetsgrad (Tabell 2).

Grad av fetma hos modern var associerat med ökande risken för spontan extrem (22-27 veckor) prematur förlossning, men inte med spontan mycket (28-31 veckor) eller spontan måttlig (32-36 veckor) för tidig förlossning. Riskerna för medicinskt indicerad (extrem, mycket och måttlig) prematur förlossning (dvs. för tidig förlossning efter induktion eller planerat kejsarsnitt) ökade med moderns övervikt och grad av fetma. Detta förklarades till största delen av en ökad förekomst av övervikts/fetma-relaterade graviditetskomplikationer (preeklampsi och graviditetsdiabetes) ${ }^{2}$.

Tabell 2. BMI och risk för preterm förlossning ${ }^{2}$.

\begin{tabular}{lcccc}
\hline & & $\begin{array}{c}\text { Extrem } \\
(22-27 \text { veckor }) \\
\text { OR (95\% CI) }\end{array}$ & $\begin{array}{c}\text { Mycket } \\
(28-31 \text { veckor }) \\
\text { OR (95\% CI) }\end{array}$ & $\begin{array}{c}\text { Måttlig } \\
(32-36 \text { veckor }) \\
\text { OR (95\% CI) }\end{array}$ \\
\hline Normal vikt & $18.5-<25$ & 1.00 & 1.00 & 1.00 \\
Övervikt & $25-<30$ & $1.2(1.1-1.4)$ & $1.1(1.05-1.2)$ & $1.04(1.02-1.06)$ \\
Fetma grad I & $30-<35$ & $1.5(1.4-1.7)$ & $1.4(1.3-1.5)$ & $1.2(1.1-1.2)$ \\
Fetma grad II & $35-<40$ & $2.0(1.6-2.4)$ & $1.8(1.6-2.0)$ & $1.30(1.2-1.4)$ \\
Fetma grad III & $\geq 40$ & $2.9(2.2-3.8)$ & $2.2(1.8-2.7)$ & $1.5(1.4-1.6)$ \\
\hline
\end{tabular}


Tabell 3. Moderns BMI förändring mellan 1:a och 2:a graviditeten och risker för neonatal mortalitet och kramper i neonatalperioden.

\begin{tabular}{|c|c|c|c|c|}
\hline \multirow[t]{3}{*}{ BMI vid 1:a graviditeten } & $<25$ & $\geq 25$ & $<25$ & $\geq 25$ \\
\hline & \multicolumn{2}{|c|}{ Neonatal mortalitet $^{10}$} & \multicolumn{2}{|c|}{ Kramper $^{11}$} \\
\hline & $\mathrm{RR}(95 \% \mathrm{CI})$ & $\mathrm{RR}(95 \% \mathrm{CI})$ & $\mathrm{RR}(95 \% \mathrm{CI})$ & RR $(95 \% \mathrm{CI})$ \\
\hline$<-2$ & $1.62(0.89-2.96)$ & $0.49(0.27-0.88)$ & $0.65(0.24-1.77)$ & $1.25(0.78-2.01)$ \\
\hline-2 till $<-1$ & $1.23(0.83-1.85)$ & $1.01(0.63-1.62)$ & $0.87(0.54-1.41)$ & $1.12(0.67-1.86)$ \\
\hline-1 till $<1$ & 1.00 & 1.00 & 1.00 & 1.00 \\
\hline 1 till $<2$ & $1.29(0.98-1.69)$ & $0.68(0.44-1.07$ & $1.21(0.91-1.61)$ & $1.00(0.65-1.54)$ \\
\hline 2 till $<4$ & $1.42(1.05-1.93)$ & $0.83(0.55-1.23)$ & $1.65(1.22-2.24)$ & $1.21(0.81-1.81)$ \\
\hline$>4$ & $1.58(0.99-2.52)$ & $0.89(0.55-1.43)$ & $2.04(1.30-3.22)$ & $0.99(0.57-1.70)$ \\
\hline P-interaktion & \multicolumn{2}{|c|}{0.04} & \multicolumn{2}{|c|}{0.004} \\
\hline
\end{tabular}

Risken för spädbarnsdöd ökade med moderns BMI för barn till överviktiga och feta kvinnor. Den BMIrelaterade ökade dödligheten var framför allt begränsad till fullgångna barn ( $\geq 37$ veckor). ${ }^{6}$ Att spädbarnsdödligheten ökar med moderns BMI beror på: a) en ökad förekomst av för tidigt födda barn; samt b) en ökad dödlighet hos fullgångna barn. Ökande BMI var associerat med en ökande risk för asfyxi-relaterad död hos fullgångna barn. Riskerna för asfyxi-relaterad sjuklighet i neonatalperioden hos fullgångna barn studerades $\mathrm{i}$ en studie. Riskerna för neonatala komplikationer, som mekonium aspiration, kramper, och låga Apgar scores vid 5 och 10 minuter ökade med moderns BMI hos barn till överviktiga och feta kvinnor ${ }^{7}$.

Att moderns fetma ökar risken för missbildningar är känt. Vi har studerat moderns BMI och riskerna för undergrupper av organ-specifika missbildningar. Vi fann att ökande fetma hos modern var associerat med ökande risker för hjärtmissbildningar, missbildningar i mag-tarm kanalen och genitala missbildningar hos pojkar ${ }^{8}$.

Om moderns övervikt och fetma är associerat med risker för mor och barn så borde förändring i exponering (förändring i moderns BMI) mellan graviditeter kunna påverka riskerna. Vi fann också ett dos-respons samband mellan viktökning från första till andra graviditeten och risker för preeklampsi, graviditetshypertoni, graviditetsdiabetes, dödföddhet, spädbarnsdöd, och asfyxi-relaterade neonatala komplikationer ${ }^{9-11}$. Effekten av viktökning var i regel mer uttalad eller begränsad till kvinnor som vid första graviditeten hade ett normalt eller lågt BMI (BMI <25) jämfört med kvinnor med högre BMI (Tabell 3).

För tidig födsel och asfyxi-relaterade sjukdomar ökar riskerna för neurologiska långtidskomplikationer hos barnet. Risken för cerebral pares (CP) hos barnet ökar med övervikt och allvarlighetsgrad av fetma. Den BMI-relaterade risken för $\mathrm{CP}$ finns framför allt hos fullgångna barn, och $71 \%$ av alla barn med $\mathrm{CP}$ var födda $\mathrm{i}$ fullgången tid $(\geq 37$ veckor). Den BMIrelaterade risken för $\mathrm{CP}$ hos fullgångna barn medieras till stor del av asfyxi-relaterade neonatala komplikationer $^{12}$. Risken för epilepsi ökar också med moderns övervikt och ökande fetma. En mindre del av denna riskökning kan förklaras av kända BMI-relaterade komplikationer under graviditet och nyföddhetsperiod $^{13}$.

\section{KONKLUSION}

Moderns övervikt och fetma är idag, på grund av den höga prevalensen och risker under graviditet, förlossning och nyföddhetsperiod, ur befolkningsperspektiv den viktigaste (åtminstone teoretiskt) förebyggbara risk faktorn under graviditet. Primär prevention, i syfte att reducera prevalensen av övervikt och fetma, har hittills inte varit särskilt framgångsrikt. Preventiva åtgärder bör inkludera insatser från såväl individer, samhälle, och livsmedelsindustri, och fokusera på hela befolkningen, inte minst barn och ungdomar. Efter förlossningen har kvinnan i regel ett återbesök till mödravårdscentralen. Då är det av stor vikt att man diskuterar strategier hur kvinnan ska reducera sin vikt till den vikt hon hade innan hon blev gravid. En minskad prevalens av övervikt och fetma bland gravida innebär sannolikt förbättrad hälsa för gravida och deras nyfödda barn.

\section{REFERENSER}

1. Dalenius K, Brindley P, Smith B, Reinold C, Grummer-Strawn L. Pregnancy Nutrition Surveillance 2010 Report. Atlanta, USA, http://www.cdc.gov/pednss/pdfs/2010-PNSS-Summary-Report.pdf.

2. Cnattingius S, Villamor E, Johansson S, Edstedt Bonamy AK, Persson M, Wikström AK, Granath F. Maternal obesity and risk of preterm delivery. JAMA 2013; 309: 2362-70.

3. Ogden CL, Caroll MD, Lawman HG, Fryar CD, Kruszon-Moran D, Kit BK, Flegal KM. Trends in obesity prevalence among children and adolescencts in the United States 1988-1994 through 2013-2014. JAMA 2016; 315: $2292-9$. 
4. Mendez MA, Monteiro CA, Popkin BM. Overweight exceeds underweight among women in most developing countries. Am J Clin Nutr 2005; 81: 714-21.

5. Poston L, Caleyachetty R, Cnattingius S, Corvalàn C, Herring S, Gillman MW. Preconceptional and maternal obesity: epidemiology and health consequences. Lancet Diab Endocrinol 2016; 4: 1025-36.

6. Johansson S, Villamor E, Altman M, Edstedt Bonamy AK, Granath F, Cnattingius S. Maternal overweight and obesity in early pregnancy and risk of infant mortality: a population-based cohort study in Sweden. BMJ 2014; 349: g6572. doi:10.1136/bmj.g6572.

7. Persson M, Johansson S, Villamor E, Cnattingius S. Maternal overweight and obesity and risks of severe birth-asphyxia-related complications in term infants: a population-based cohort study in Sweden. PLoS Med 201411 (5): e1001648. doi:10.1371/journal.pmed.1001648.

8. Persson M, Cnattingius S, Villamor E, Söderling J, Pasternak B, Stephansson O, Neovius M. Risk of major congenital malformations in relation to maternal overweight and obesity severity: cohort study of 1.2 million singletons. BMJ 2017; 357: j2563.

9. Villamor E, Cnattingius S. Interpregnancy weight change and risk of adverse pregnancy outcomes: a population-based study. Lancet 2006; 368: 1164-70.

10. Cnattingius S, Villamor E. Weight change between successive pregnancies and risks of stillbirth and infant mortality: a nation-wide cohort study. Lancet 2016; 24: 727-34.

11. Persson M, Johansson S, Cnattingius S. Inter-pregnancy weight change and risks of severe birth asphyxiarelated outcomes in singleton infants born at term: a nationwide Swedish cohort study. PLOS Med 2016; 13 (6): e1002033. doi: 10.137/journal.pmed.1002033.

12. Villamor E, Tedroff K, Peterson M, Johansson S, Neovius M, Petersson G, Cnattingius S. Association between maternal body mass index in early pregnancy and incidence of cerebral palsy. JAMA 2017; 317: 925-36.

13. Razaz N, Tedroff K, Villamor E, Cnattingius S. Maternal body mass index in early pregnancy and risk of epilepsy in offspring. JAMA Neurology 2017; 74: 668-76. 